\title{
Evidência da ação de microorganismos na ramificaçào de raízes
}

\author{
Ted St. John (") \\ Antonio Dantas Machado (**)
}

\begin{abstract}
Resumo
A proliferação de raizes em matéria orgânica é um componente importante no ciclo de nutrientes nas florestas tropicais úmidas. Neste trabalho foi realizada uma tentativa de definir um possível mecanismo de controle dessa proliferaçăo. Folhas parcialmente decompostas da leguminosa Clitoria racemosa foram esterillzadas e colocadas em vidros com plântulas da mesma espécie. Uma metade dos vidros fol inoculada com terra contendo bactérias e fungos da liteira. A outra metade recebeu porçōes do material esterlizado. As plântulas com inóculo vivo produziram em média $106 \pm 30$ pontas de raiz por plântula, enquanto as com inóculo esterilizado produziram $60 \pm 12$ pontas de raiz. Concluiu-se que um componente biótico da matéria orgânica decomposta é capaz de induzir ramlficaçẫo de raízes, provavelmente por meio de um hormônio como etileno ou auxina.
\end{abstract}

\section{INTRODUÇÃo}

A proliferação de raízes no horizonte superior do perfil do solo e na matéria orgânica da superfície é uma componente importante no ciclo de nutrientes nas florestas tropicais úmidas. A associação raiz-fungo, conhecida como micorriza, forma um denso sistema de absorção que deixa poucos nutrientes minerais escaparem de sua zona de atuação (Went \& Stark, 1968; Richards, 1952), principalmente fósforo, se essas micorrizas forem do tipo "vesicular-arbuscular" (Mosse, 1973). O conhecimento mais completo dos mecanismos envolvidos nesse processo poderia melhor orientar o manejo contínuo (cultivos perenes) dos solos, geralmente pouco férteis, da Amazônia. Uma série de investigações está sendo conduzida sobre a interrelação entre os fenômenos da proliferação de raízes, crescimento de micorrizas e absorção de nutrientes na floresta amazônica primária. Neste trabalho relata-se um experimento preliminar, no qual se tentou induzir, artificialmente, o crescimento de raizes em matéria orgânica estéril, com e sem inoculação de microorganismos do solo. Sabese que os microorganismos influenciam a morfologia das raízes (Rovira \& Davey, 1974) e é razoável supor-se que as grandes populações de microorganismos presentes na matéria orgânica da floresta são, pelo menos parcialmente, responsáveis pela proliferação de raízes observada. O propósito original deste experimento foi o de testar um possível efeito das micorrizas vesicular-arbusculares sobre a proliferação de raizes; todavia, a informação mais interessante do experimento foi obtida sobre os organismos contaminadores e é com base neste fato que os resultados são discutidos.

\section{MATERIAL E MÉTODOS}

A planta testada foi Clitoria racemosa (Fabaceae), uma espécie nativa da Amazônia (Prance \& da Silva, 1975). Suas raízes proliferam abundantemente na liteira de suas próprias folhas e os espécimem adultos são portadores de micorrizas. Em maio de 1977 foram coletadas sementes de frutos recém-caídos, os quais foram esterilizados por 10 minutos numa mistura de $10 \%(\mathrm{v} / \mathrm{v})$ de água sanitária e água, enxaguadas em água esterilizada e postas para germinar em placa de petri forradas com papel de filtrc úmido. As sementes germinadas, e isentas de contaminação aparente, foram então transferidas para pequenos copos de vidro de aproximadamente $200 \mathrm{ml}$ de capacidade, tendo como substrato areia lavada e esterilizada numa camada de $2 \mathrm{~cm}$ e acima desta camada uma sutra de matéria orgânica, com $3 \mathrm{~cm}$ de espessura. A matéria orgânica consistiu de folhas de plantas adultas de Clitoria racemosa. Antes

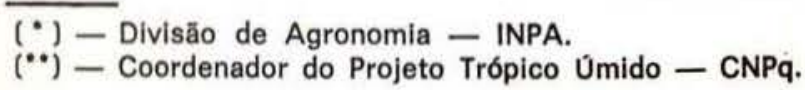


da transferência das sementes germinadas, o substrato recebeu no seu centro $1 \mathrm{ml}$ de inóculo vivo ou esterilizado a vapor. O inóculo de microorganismos consistiu de fração peneirada, entre 50 a 100 micra, de solo coletado nos primeiros $5 \mathrm{~cm}$ do perfil, debaixo das árvores de C. racemosa. Esse material continha numerosos esporos de uma ou mais espécies de fungos micorrizais do gênero Glomus (Gerde. mann \& Trappe, 1974), partículas de matéria orgânica e bactérias e fungos associados.

Os recipientes, em seu terço inferior pro tegidos para evitar penetração de luz na zona das raizes, foram dispostos em mesa de laboratório onde a temperatura oscilou entre $20 \mathrm{e}$ $25^{\circ} \mathrm{C}$ durante o período de crescimento das plântulas ( 31 dias). Não foi realizada nenhuma tentativa para manter as culturas totalmente livres de contaminações do ambiente, embora contaminações grosseiras tenham sido evitadas pelo uso de coberturas transparentes aplicadas aos recipientes. Para cada tratamento (inóculo vivo ou inóculo esterilizado) foram utilizadas 8 repetições.

Ao final do periodo de observação foram coletados os seguintes dados: número total de raizes (que se assumiu como uma medida de ramificação); peso seco do sistema radicular e peso seco da parte aérea, incluindo os cotilédones. A infestação por micorrizas foi esti- mada pelo método de Phillips \& Hayman (1970), em todas repetiçōes inoculadas e em apenas duas repetições ccriı inóculo esterilizado.

\section{RESULTADOS E DISCUSSÃO}

Não foram detectadas diferenças significantes entre os tratamentos no que se refere a ganho de peso pelo sistema radicular ou parte aérea das plântulas. Por outro lado, encontrouse uma diferença significativa no número de pontas das raízes (Quadro I). Um exame das preparações de raízes mostrou que, com exceção de apenas um caso, não havia infestação por micorrizas. Ainda no caso positivo, verificou-se que a infestação estava em estágio inicial e provavelmente não suficientemente estabelecida para ter influenciado o crescimento da raiz. Assim, as diferenças observadas, quanto à ramificação, devem ter sido causadas por outros microorganismos ou por produtos termolábeis do inóculo. Uma grande variabilidade no número de pontas de raízes foi observada no tratamento com inóculo vivo, embora todas, exceto uma das réplicas, apresentassem mais pontas de raízes do que a mais ramificada do tratamento controle. Essa variabilidade seria esperada em experimento a curto prazo, no qual os resultados são influenciados pelo estabelecimento e crescimento de microorganis. mos-chave. Na realidade, se o princípio ativo

QUADRO 1 - Peso seco de raízes, parte á́rea, relaçăo raiz/parte aérea e número de pontos de raízes em plântulas de Clitória racemosa

\begin{tabular}{l|c|c|c|c}
\hline $\begin{array}{c}\text { Parảmetros } \\
\text { observados } \\
\text { Tratamento }\end{array}$ & $\begin{array}{c}\text { Peso seco } \\
\text { de } \\
\text { raizes g. }\end{array}$ & $\begin{array}{c}\text { Peso seco } \\
\text { raiz/ } \\
\text { Parte aérea }\end{array}$ & $\begin{array}{c}\text { Relaçắo } \\
\text { raiz/ } \\
\text { Parte aérea }\end{array}$ & $\begin{array}{c}\text { Número de } \\
\text { pontas de } \\
\text { raizes }\end{array}$ \\
\hline $\begin{array}{l}\text { In6́culo } \\
\text { Esterilizado }\end{array}$ & $0,032 \pm 0,012$ & $0,341 \pm 0,063$ & $0,094 \pm 0,035$ & $60 \pm 12$ \\
\hline In6́culo & $0,046 \pm 0,034$ & $0,335 \pm 0,056$ & $0,137 \pm 0,069$ & $106 \pm 30$ \\
\hline
\end{tabular}


do inóculo fosse uma substância termolábil, já presente, a variabilidade certamente apresentaria outros resultados, fato que reforça a hipótese da presença ativa de microorganismos de contaminação, envolvidos no processo de ramificação radicular.

A capacidade de microorganismos produzi. rem metabólitos que podem induzir a ramificação ou iniciação de raízes laterais é fato conhecido. Essas substâncias podem ser auxinas, dióxido de carbono, etileno (Street, 1969) e nutrientes minerais (Miller, 1974). Rovira \& Davey (1974) relataram exemplos tanto de estimulação quanto de inibição de raízes laterais por microorganismos. A cuncentração localizada de matéria orgânica, tal como a que ocorre na superfície e nas camadas superiores dos solos das florestas tropicais úmidas é capaz de comportar populações muito maiores de microorganismos que os solos adjacentes que têm menor quantidade de matéria orgânica (Alexander, 1961) .

Experimentos adicionais, no campo e no laboratório, estão em andamento, para separar os tipos de fatores, orgânicos ou inorgânicos, que influenciam a proliferação de raízes e para elucidar quanto aos possiveis fatores do ambiente físico e aspectos genéticos que possam ser determinantes importantes do crescimento de raizes.

\section{SUMMARY}

Proliferation of roots in organic matter is an important component of tropical nutrient cycling. In an attempt to define possible mechanisms controlling this proliferation, an experiment was conducted in which seedlings of the legume Clitoria racemosa were planted in vessels with sterilized partially decayed leaves of the same species. One half of the vessels was inoculated with a material containing litter bacteria and fungi and the other half with sterilized portions of the same material. Those having received live inoculum produced $106 \pm 30$ root tips per plant against $60 \pm 12$ with sterilized inoculum. It is concluded that a biotic component of decomposing organic matter is able to induce branching of roots, probably through production of a hormone such as ethylene or an auxin.

\section{Bibliografia CITADA}

Alexander, Martin

1961 - Introduction to Soil Microbiology. John Wiley \& Sons, Inc. New York.

Gerdemann, J. W. \& Trappe, J. M.

1974 - The Endogonaceae in the Pacific Northwest. Mycologia Memoir, $n^{\circ} 5$.

MiLleR, M. H.

1974 - Effects of Nitrogen on Phophorus Absorption by Plants. In: Carson, E. W., ed. - The Plant Root and its Environment. University of Virginia Press, Charlottesville.

Mosse, B.

1973 - Advances in the Study of Vesicular-arbuscular Mycorrhiza. A. Rev. Phytopath, 11: 171-196.

Phillips, J. M \& Hayman, D. S.

1970 - Improved Procedures for Clearing Roots \& Staining Parastic and Vesicular-arbuscular Mycorrhizal Fungi for Rapid Assesment of Infection. Trans. Br. Mycol. Soc., 55 : 158-161.

Prance, G. T. \& Silva, Marlene F. da

1975 - Árvores de Manaus - Conselho Nacional de Desenvolvimento Cientifico e Tecnológico (CNPq); Instituto Nacional de Pesquisas da Amazônia, Manaus.

RICHARDS, P. W.

1952 - The Tropical Rain Forest. Cambridge, Unlversity Press.

Rovira, A. D. \& Davey, C. B.

1974 - Biology of the Rhizosphere. In: Carson, E. W., ed. The Plant Root and its Environment. University Press of Virginia, Charlottesville.

Street, H. E.

1969 - Factors Influencing the Initiation and Activity of Meristems in Roots. In: Whittington, W. J., ed. Root Growth. New York, Plenum Press.

Went, F. W. \& Stark, N.

1968 - Mycorrhiza. Bioscience, 18 : 1035-1039. 